\title{
Etika Penerapan Bahasa Indonesia dalam Bidang Bisnis (Perdagangan) di SMP Negeri 17 Depok
}

\author{
Aster Pujaning Ati ${ }^{1 *}$, Rully Noor Oktaviana ${ }^{2 *}$, Nur Sodik ${ }^{3}$ \\ ${ }^{123}$ Universitas Indraprasta PGRI \\ asterpujaningati@ymail.com, ully.unpad@gmail.com
}

\begin{abstract}
Abstrak
Salah satu dasar penerapan pengembangan bahasa Indonesia dalam kurikulum pendidikan nasional adalah karena adanya keberagaman budaya dan bahasa yang ada di masyarakat di setiap daerah. Sekolah Menengah Pertama Negeri (SMPN) yang terdiri dari pelajaran Ilmu Pengetahuan Sosial materi ekonomi adalah objek yang akan dijadikan lokasi pelaksanaan pengabdian terhadap masyarakat. Mengingat pentingnya pelajaran IPS materi ekonomi yang akhir-akhir ini menjadi sorotan dalam praktik berwirausaha sejak dini, maka kiranya praktik istilah bahasa dalam dunia bisnis/perdagangan sangat dibutuhkan. The 1st Education and Language International Conference Proceedings Center for International Language Development of Unissula memaparkan bahwa dengan diterapkannya MEA, arus produk ekonomis, informasi, dan perdagangan akan masuk dengan cepat tiada batas. Bahasa Indonesia sebagai bahasa perdagangan harus bersifat persuasif di mana bisa mempengaruhi dan mengajak orang lain untuk membeli produk barang dan jasa yang ditawarkan. Bahasa Indonesia harus mempunyai nilai jual sehingga masyarakat tertarik untuk membeli produk yang ditawarkan.
\end{abstract}

Kata Kunci: etika penerapan bahasa Indonesia, bidang bisnis (perdagangan)

\section{Application Ethics of Indonesian Language in The Field of Business (Trade) in The State Junior High School 17 Depok}

\begin{abstract}
One of the basic applications of the development of Indonesian language in the national education curriculum is due to the diversity of cultures and languages that exist in the community in each region. towards the community. Considering the importance of social studies courses in economic material which has recently become a highlight in the practice of entrepreneurship from an early age, it is likely that the practice of the term language in the business / trade world is very much needed. with the implementation of the AEC, the flow of economic products, information, and trade will enter quickly without limits. Indonesian as a trade language must be persuasive which can influence and encourage others to buy the products and services offered. Indonesian language must have a sale value so that people are interested in buying the products offered.
\end{abstract}

Keywords: application ethics of indonesian language, field of business (trade)

\section{PENDAHULUAN}

Berbagai aspek dari segala bidang akan masuk ke Indonesia. Selain di bidang ekonomi, bahasa merupakan media yang paling penting dalam hal komunikasi baik individu maupun kelompok di lingkungan Masyarakat Ekonomi Asean. Indonesia akan menjadi pangsa pasar yang besar bagi komunitas Asean. Hal ini menuntut peran bahasa Indonesia yang akan dijadikan bahasa dalam hal perekonomian terutama perdagangan. Penelaahan yang dilakukan berdasarkan berbagai aspek dan pandangan. Salah satunya ditinjau dari sejarah, di mana bahasa Melayu sebelum dijadikan bahasa Indonesia merupakan bahasa perhubungan dalam hal perdagangan Singapura, Johor, dan Riau yang merupakan daerah serumpun serta dikenal dengan segitiga emas perdagangan. Dengan demikian bahasa Indonesia harus menjadi peran sentral bahkan bahasa utama dalam bahasa 
perdagangan di Masyarakat Ekonomi Asean (MEA). Untuk itu, sekolah sebagai salah satu institusi pendidikan formal, hendaknya menyiapkan segala perangkat pembelajaran yang dibutuhkan oleh peserta didik.

Zulfadhli, Asnawi, dan Hardani (2017) memaparkan bahwa dengan diterapkannya MEA, arus produk ekonomis, informasi, dan perdagangan akan masuk dengan cepat tiada batas. Indonesia diharapkan mampu menyiapkan sumber daya manusia yang ada. Modal utama yang dimiliki Indonesia adalah bahasa. Bahasa Indonesia dinyatakan sebagai bahasa persatuan dan lambang identitas nasional. Sebagai bahasa persatuan dan lambang identitas nasional bahasa Indonesia berperan dapat mengembangkan ilmu pengetahuan dan budaya Indonesia untuk diketahui masyarakat luas, terutama masyarakat Asean. Fenomena ini mengakibatkan pentingnya bahasa Indonesia dalam masyarakat ekonomi ASEAN, khususnya dalam bidang perdagangan. Di era MEA bahasa Indonesia sebagai bahasa perdagangan berperan untuk melakukan persuasif terhadap penjualan dan penawaran produk dan sebagai bahasa pengantar dalam melakukan transaksi dan promosi, yang paling banyak berpengaruh dan sangat ditekan dalam Masyarakat Ekonomi Asean adalah sumber daya manusia yang berkompeten.

\section{Bahasa Indonesia sebagai Bahasa Perdagangan Bersifat Persuasif}

Bahasa Indonesia sebagai bahasa perdagangan harus bersifat persuasif di mana bisa mempengaruhi dan mengajak orang lain untuk membeli produk barang dan jasa yang ditawarkan. Bahasa Indonesia harus mempunyai nilai jual sehingga masyarakat tertarik untuk membeli produk yang ditawarkan. Selain kemasan dan isi yang menarik, bahasa jauh lebih penting dalam mempengaruhi orang lain membeli produk barang atau jasa yang ditawarkan. Hal ini memberikan tantangan bagi pemerintah dan pengusaha untuk membuat bahasa produk berupa barang dan jasa yang menarik serta dapat mempengaruhi orang lain untuk membeli produk barang dan jasa yang ditawarkan.

\section{Tinjauan Sejarah Bahasa Indonesia sebagai Bahasa Perdagangan.}

Bahasa Indonesia memiliki peran yang sangat besar jika dijadikan bahasa perdagangan di era MEA. Hal ini diutarakan pada akhir tahun 2010, Ketua Dewan perwakilan Rakyat Indonesia secara terbuka mengusulkan agar bahasa Indonesia menjadi salah satu bahasa resmi Asean. Bahasa Indonesia telah digunakan sejak dahulu sebagai bahasa komunikasi dan perdagangan di antara Negara-negara Asean atau lebih dikenal dengan negara serumpun. Melalui kesamaan dalam hal komunikasi membuat ikatan emosional negara-negara semakin kuat dalam melakukan peran perdagangan karena saling memahami maksud yang ingin disampaikan. Hal ini membuat komunikasi menjadi efektif dan efisien. Melalui peristiwa sejarah perdagangan masa lalu, membuat kita yakin bahwa bahasa Indonesia layak untuk dijadikan bahasa perdagangan di era MEA.

\section{Penguatan Identitas Bahasa Indonesia}

Syukrini'am (2015) memaparkan bahwa semakin meluasnya pengaruh globalisasi, menyebabkan Indonesia akan membuka lebar berbagai macam akses ekonomi dan sumber daya manusia yang sebelumnya terdapat penghalang. Menyebabkan semakin banyak barang, jasa, dan tenaga kerja dari negara lain yang masuk ke Indonesia yang tentu saja akan bersaing untuk memperebutkan hati konsumen dan pemilik usaha atau modal Indonesia. Sumber daya manusia Indonesia 
Vol. 1, No. 2,

July 2020

pp. $40-46$

e-ISSN:

2722-2004

\section{Title}

Application

Ethics of

Indonesian

Language in

The Field of

Business

(Trade) in The

State Junior

High School

17 Depok

Author

A. P. Ati,

R. N. Oktaviana,

N. Sodik

harus mempersiapkan diri menghadapi persaingan tersebut. Dampaknya adalah semakin meluasnya bahasa Inggris sebagai bahasa interaksi internasional. Masyarakat Indonesia harus mempertahankan bahasa Indonesia yang merupakan identitas bangsa Indonesia. Masyarakat hanya perlu menggunakan bahasa Indonesia dengan baik dan benar serta adanya rasa bangga menggunakannya. Dengan begitu, masyarakat Indonesia dapat menghadapi arus globalisasi dengan lebih percaya diri dan turut aktif memengaruhi budaya bangsa-bangsa lain yang akan masuk ke Indonesia, bukannya terpengaruh oleh negara lain.

\section{Pendidikan}

Pendidikan merupakan salah satu bidang yang paling berpengaruh dalam upaya mempertahankan wibawa bahasa Indonesia. Penggunaan bahasa Indonesia yang baik dan benar harus mulai ditanamkan pada peserta didik sejak memasuki sekolah formal, baik di tingkat SD, SMP, maupun SMA. Hal ini dapat dilakukan dengan syarat guru telah menggunakan bahasa Indonesia yang baik dan benar, sehingga guru dapat memperhatikan kecakapan berbahasa Indonesia peserta didiknya. Dalam hal ini, guru harus memulai dengan memberikan contoh penggunaan bahasa Indonesia yang baik saat menjalin komunikasi dengan peserta didik. Selain itu, guru selalu memperhatikan dan memberi masukan kepada peserta didik tentang kecakapan berbahasa Indonesia, baik bahasa lisan maupun bahasa tulis.

Salah satu dasar penerapan pengembangan bahasa Indonesia dalam kurikulum pendidikan nasional adalah karena adanya keberagaman budaya dan bahasa yang ada di masyarakat di setiap daerah. Keberagaman ini mendorong beragamnya bahasa, baik bahasa lokal ataupun bahasa internasional yang diambil oleh setiap sekolah. Sebagai pendidikan bahasa daerah atau bahasa asing berdasarkan keadaan dan kebutuhan daerah setempat. Sekolah Menengah Pertama Negeri (SMPN) 17 Depok yang terdiri dari pelajaran Ilmu Pengetahuan Sosial materi ekonomi adalah objek yang akan dijadikan lokasi pelaksanaan pengabdian terhadap masyarakat. Mengingat pentingnya pelajaran IPS materi ekonomi yang akhir-akhir ini menjadi sorotan dalam praktik berwirausaha sejak dini, maka kiranya praktik istilah bahasa dalam dunia bisnis/perdagangan sangat dibutuhkan. Untuk itu diperlukan kajian dan pengembangan perangkat pembelajaran, yaitu Rencana Pelaksanaan Pembelajaran (RPP), Silabus dan Bahan Ajar. Dengan demikian, peserta didik dapat mudah mengasosiasikan pelajaran bahasa Indonesia dengan kebutuhan riil mereka; baik kebutuhan saat praktik maupun dalam dunia kerja. Selain itu, dengan perangkat pembelajaran yang disesuaikan dengan kebutuhan keterampilan peserta didik yang nantinya akan digunakan didunia kerja, mereka akan lebih mudah berkomunikasi dengan Bahasa Indonesia baik lisan maupun tulis diera global ini.

\section{METODE PELAKSANAAN}

Pengabdian masyarakat ini memberikan pelatihan keterampilan dengan metode praktik langsung dengan tahapan berikut. 


\section{Perencanaan}

Pada tahap ini perencanaan dimulai dari penemuan masalah yang terjadi di lapangan dengan cara melakukan kegiatan pretest dan hasilnya, kemudian merancang tindakan yang akan dilakukan.

\section{Tindakan}

Melaksanakan tindakan sesuai dengan skenario yang telah direncanakan, serta mengidentifikasi masalah pada mitra kegiatan.

\section{Refleksi}

Refleksi dilakukan sebagai upaya untuk mengoreksi masalah yang muncul yang terjadi selama pelaksanaan tindakan dengan cara mengadakan posttest.

Pelaksanaan tersebut disusun berdasarkan beberapa penyesuaian kerja yang dibutuhkan dan kemudian tim pelaksana membuat kategori penugasan.

\section{Pelaksanaan Kegiatan}

\section{Informasi Mitra}

Tim pelaksana mencari tahu informasi terkait SMP Negeri 17 Depok untuk memperkirakan kebutuhan mitra. Dari hasil pembahasan tim, didapat data mengenai kebutuhan peserta didik di lingkungan sekolah. Minimnya sarana yang menunjang untuk belajar Bahasa Indonesia juga menjadi sorotan tim pelaksana.

\section{Partisipasi Mitra}

Partisipasi mitra dalam pelaksanaan program adalah menyediakan lokasi dan peserta abdimas untuk turut serta dalam proses perencanaan hingga uji coba prototipe.

\section{Pelaksanaan Kegiatan Sosialisasi}

a. Pelaksanaan Kegiatan Sosialisasi

Pelaksanaan kegiatan kelas menulis dan berbicara dilakukan dalam 6 kali pertemuan. Pertemuan dilaksanakan dua kali seminggu dengan durasi waktu 2x60 menit.

Tabel 1. Kegiatan Sosialisasi

\begin{tabular}{|c|c|c|}
\hline Pertemuan & Kegiatan sosialisasi & Tim Pelaksana \\
\hline 1 & $\begin{array}{lcc}\text { Perkenalan } & \text { dan } & \text { tahapan } \\
\text { penjelasan } & \text { mengenai } & \text { PKM }\end{array}$ & Semua Tim Abdimas \\
\hline & $\begin{array}{l}\text { Etika Penerapan Bahasa } \\
\text { Indonesia }\end{array}$ & \\
\hline 2 & Pre Test & Semua Tim Abdimas \\
\hline 3 & Menulis dan Berbicara & Aster Pujaning Ati \\
\hline 4 & Evaluasi Kegiatan sosialisasi & Semua Tim Abdimas \\
\hline
\end{tabular}

Sumber: Diolah (2020) 
Vol. 1, No. 2,

July 2020

pp. 40-46

e-ISSN

2722-2004

\section{Title}

Application

Ethics of

Indonesian

Language in

The Field of

Business

(Trade) in The

State Junior

High School

17 Depok

Author

A. P. Ati,

R. N. Oktaviana,

N. Sodik

Kegiatan sosialisasi ini dilaksanakan selama 5 minggu agar peserta kegiatan semakin mahir dalam Menulis dan Berbicara dalam PKM Etika Penerapan Bahasa Indonesia mereka.

b. Peserta Kegiatan Sosialisasi

Peserta kegiatan sosialisasi ini adalah seluruh guru-guru dan peserta didik di SMP Negeri 17 Depok.

\section{c. Fasilitas Kegiatan Sosialisasi}

Fasilitas untuk kegiatan sosialisasi seperti laptop, papan tulis atau whiteboard dan proyektor disediakan sesuai kebutuhan, baik dari SMP Negeri 17 Depok maupun dari Tim Abdimas.

\section{HASIL DAN PEMBAHASAN}

Pelaksanaan kegiatan pengabdian masyarakat ini dilaksanakan dengan metode sosialisasi yang melibatkan para guru dan peserta didik di SMP Negeri 17 Depok. Kegiatan dilakukan dengan menggunakan metode ceramah, diskusi, dan praktik langsung ke kelas menerapkan materi etika penerapan bahasa Indonesia dalam bidang bisnis (perdagangan). Agar tujuan sosialisasi berjalan sesuai dengan harapan, maka dilakukan langkah-langkah sosialisasi sebagai berikut;

1. Dilaksanakan kegiatan sosialisasi tentang etika penerapan bahasa Indonesia dalam bidang bisnis (perdagangan). Sosialisasi ini menggunakan metode ceramah yang berisikan tentang,

a. Apa itu etika?

b. Apakah yang dimaksud dengan penerapan bahasa Indonesia dalam bidang bisnis (perdagangan)?

c. Peranan guru dalam kelas mendampingi siswa.

d. Kebutuhan peserta didik dalam penerapan bahasa Indonesia dalam bidang bisnis (perdagangan).

2. Kegiatan diskusi dengan para guru mengenai peranan yang dapat mereka ambil sehingga peserta didik semakin mahir dalam Menulis dan Berbicara dalam Etika Penerapan Bahasa Indonesia.

3. Melakukan pilihan terhadap materi etika penerapan bahasa Indonesia dalam bidang bisnis (perdagangan) yang akan digunakan dan disesuaikan dengan kemampuan peserta didik. Diputuskan untuk memakai kelas VIII sebagai kelas percontohan dengan jumlah 40 peserta didik. Materi yang dimanfaatkan tidak hanya berisikan teks tetapi juga penuh dengan ilustrasi dan gambar-gambar dengan warna-warna yang menarik sehingga diharapkan peserta didik lebih tertarik dalam kegiatan.

4. Melaksanakan kelas percontohan Menulis dan Berbicara dalam Etika Penerapan Bahasa Indonesia dengan memanfaatkan buku yang sudah dipilih sebelumnya. Kelas percontohan ini dibagi ke dalam dua sesi yaitu,

a. Kelas Menulis.

Kelas ini bertujuan untuk melatih peserta didik Menulis dengan benar dan menyusun kalimat yang mudah dipahami. 
b. Kelas Berbicara.

Kelas ini mengajarkan peserta didik bagaimana berbicara yang baik sesuai dengan etika penerapan bahasa Indonesia dalam bidang bisnis (perdagangan). Selain itu, peserta didik juga diminta mempraktikkan materi yang sudah dipelajari dengan teknik maju ke depan satu per satu.

5. Melakukan diskusi dengan para guru tentang hambatan-hambatan yang dirasakan peserta didik dalam kelas membaca ekstensif dan merumuskan solusinya.

Rangkaian kegiatan sosialisasi ini dilaksanakan dalam beberapa tahapan dengan tujuan agar guru memahami mengenai materi etika penerapan bahasa Indonesia dalam bidang bisnis (perdagangan) yang dapat mengembangkan berbagai keahlian berbahasa peserta didik. Selain itu, para guru juga dapat mengembangkan kemampuan mereka dalam membuat kegiatan pembelajaran yang menarik bagi peserta didik. Pada kelas percontohan, dilaksanakan juga tes kepada peserta didik untuk melihat hasil kelas menulis dan berbicara yang sudah mereka dapatkan selama 4 kali pertemuan.

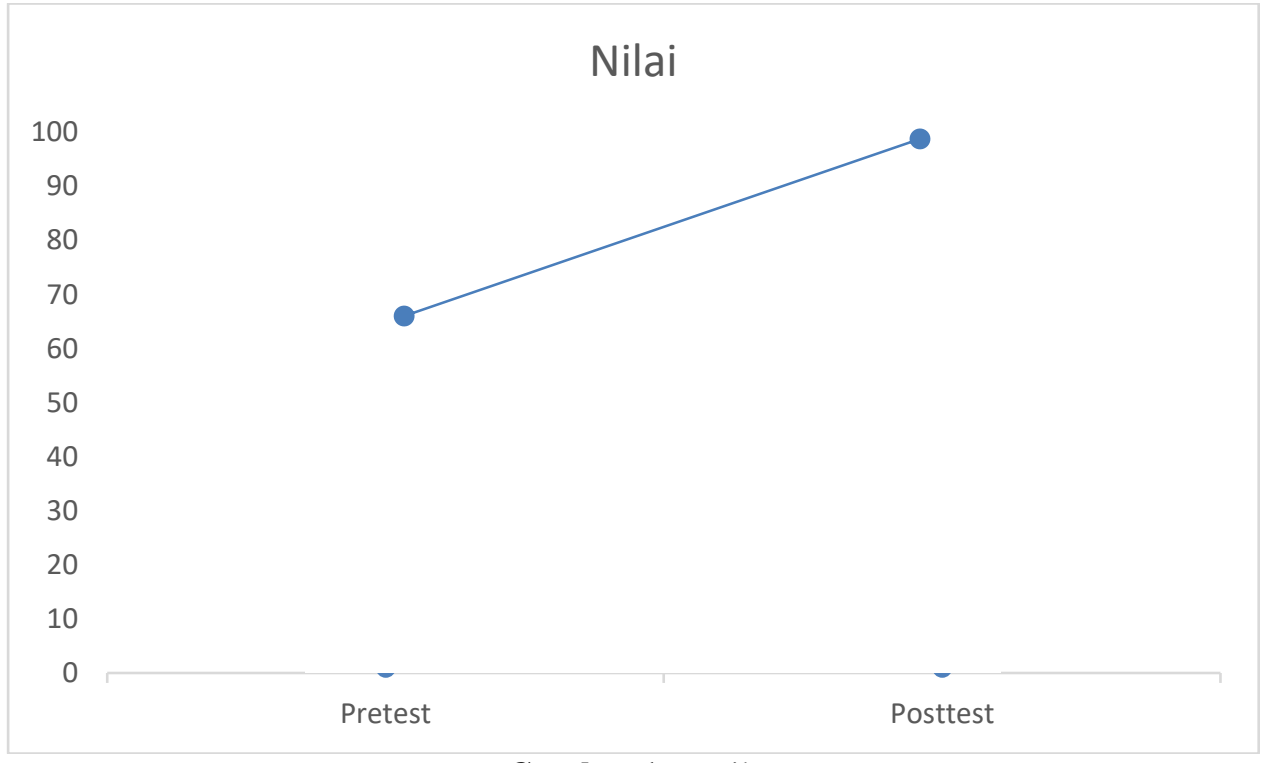

Gambar 1. Hasil Tes

Hasil tes dari kedua kelas memperlihatkan bahwa kelas pretest sebelum materi etika penerapan bahasa Indonesia dalam bidang bisnis (perdagangan) disampaikan memiliki rata-rata 63,75. Sedangkan kelas posttes setelah materi etika penerapan bahasa Indonesia dalam bidang bisnis (perdagangan) disampaikan memiliki rata-rata 91,75. Guru-guru pada SMP Negeri 17 Depok menyatakan sangat berhasil pada peserta didik mereka mengingat pelajaran bahasa Indonesia pada kompetensi menulis dan berbicara. Guru-guru juga merasakan kompetensi menulis dan berbicara pada peserta didik mereka berkembang dengan lebih baik dengan menggunakan latihan-latihan yang diberikan pada kelas percontohan ini.

Beberapa hal yang menjadi evaluasi pada kegiatan sosialisasi etika penerapan bahasa Indonesia dalam bidang bisnis (perdagangan) ini adalah;

1. Penguasaan guru terhadap materi ajar yang dapat memotivasi peserta didik sangatlah minim sehingga tim Abdimas perlu memberikan contoh-contoh materi dan latihan yang dapat mereka gunakan. 
KANGMAS: Karya Ilmiah Pengabdian Masyarakat, 1 (2), July 2020 - 46

http://journal.neolectura.com/index.php/Kangmas

2. Pada kelas membaca keras, guru dan tim abdimas membutuhkan sedikit usaha dalam meminta peserta didik membaca kalimat-kalimat yang diminta karena mereka merasa malu jika melakukan kesalahan pelafalan. Solusi yang ditawarkan adalah melakukan membaca keras secara bersama-sama sehingga semua siswa ikut serta melafalkan kalimat-kalimat yang ada pada buku.

e-ISSN:

2722-2004

Title

Application

Ethics of

Indonesian

Language in

The Field of

Business

(Trade) in The

State Junior

High School

17 Depok

Author

A. P. Ati,

R. N. Oktaviana,

N. Sodik

\section{SIMPULAN}

Kegiatan sosialisasi menulis dan berbicara dengan materi etika penerapan bahasa Indonesia dalam bidang bisnis (perdagangan) disimpulkan berhasil dengan mempertimbangkan adanya respons positif dari para guru peserta sosialisasi yang bersedia hadir dalam setiap kegiatan dan memberikan salah satu kelas mereka sebagai kelas percontohan yang digunakan selama 6 kali pertemuan.

\section{DAFTAR PUSTAKA}

Zulfadhli, M., Asnawi, \& Hardani, M. (2017). Peran Bahasa Indonesia sebagai Bahasa Perdagangan di Era MEA. The 1st Education and Language International Conference Proceedings Center for International Language Development of Unissula, 508-515. Diakses dari http://jurnal.unissula.ac.id/index.php/ELIC/article/download/1267/975

Syukrini'am, W. (2015). Penguatan Identitas Bahasa Indonesia sebagai Lambang Identitas Nasional dan Bahasa Persatuan dalam Era Global. Program Pascasarjana Pendidikan Bahasa Indonesia Universitas Sebelas Maret Surakarta. Prosiding Konferensi Nasional Bahasa dan Sastra III. Diakses dari http://s3pbi.fkip.uns.ac.id/wp-content/uploads/2016/01/WildanSyukri.pdf

Aziz, A. L. 2014. Serbuan Bahasa Inggris dalam Iklan Perdagangan dan Pengaruhnya terhadap Rasa Percaya Diri Bangsa Indonesia di Antara Bangsa Lain. Disampaikan dalam Konferensi Linguistik 2014 oleh Universitas Airlangga. Diakses dari http://lp2m.um.ac.id/wpcontent/uploads/2014/03/31.pdf 